\title{
Logistics in the Health Care System: The Case of Greek Hospitals
}

\author{
Ioannis Kafetzidakis \& Athanassios Mihiotis (Corresponding author) \\ School of Social Sciences, Hellenic Open University, 57-59 Bouboulinas Str., 26222 Patras, Greece \\ E-mail: gianniskafes@yahoo.gr,mihiotis@eap.gr
}

Received: June 28, 2012

Accepted: August 29, 2012

Online Published: September 12, 2012

doi:10.5430/ijba.v3n5p23

\author{
URL: http://dx.doi.org/10.5430/ijba.v3n5p23
}

\begin{abstract}
Medical logistics is used as a tool for measuring performance and improving operations and is a topic of worldwide increasing importance. In Greece the implementation of such applications is relatively limited and there is therefore a significant scope for study. The fact that the cost of health care treatment has substantially increased over time due to over-spending of medical supplies, makes the need of identifying the factors which lead to such situations imperative. The research presented in this paper is a first attempt to identify the level of awareness of logistics that hospitals in Greece have. In fact, recently the majority of the larger Greek hospitals faced serious deficiencies in medical supplies due to their insolvency. The purpose of this paper is to examine the distribution process of supplies, the amount or the volume of distributed medicines and the degree of partnerships between Greek hospitals and their vendors. In addition, we monitor the extent of responsibility given to the logistics departments (if they do exist) with respect to purchasing, inventory management, internal distribution to medical departments and management information systems.
\end{abstract}

Keywords: Medical logistics, Supplies, Health care system, Supply chain, Greek hospitals

\section{Introduction}

Medical Logistics includes the supply of pharmaceutical, medical, surgical consumables, medical devices and equipment and other supplementary products necessary to support doctors, the nurses and of course patients of the hospitals (http/en.wikipedia/org/wiki/medial/logistics). Hygiene consumables and food supplies are also included. Due to the fact that the end users are responsible for the lives and the health of their patients, medical logistics is unique as it aims to improve the effectiveness and not the efficiency. The procedures of medical logistics are a big part of the health care system. In fact, the second highest health care cost after personnel is the cost of medical supplies.

Surveys have shown that $30 \%$ to $50 \%$ of a hospitals' budget is committed to materials, consumables, equipment and outsourcing. Half of the above percentage comes from the direct cost of buying material and services and the other half from after sales management. In the recent past the inventory and supplies management was not a significant field for hospitals and there was not almost any plan for these procedures (Bowersox and Closs, 1996). As a result the hospitals' costs started to rise significantly and when these costs reached a very high level, the centralized material management seemed to be the only solution (Hansen and Mowen, 1997). Health care systems appear to be the last industry sector to follow well established methods for controlling expenses. During the 80's great importance was given to acquiring mass supplies and central inventory management (Nickolson et al., 2004). Furthermore the increasing dependence on the suppliers for the delivery of additional services like the suppliers' internal inventory management and the just in time delivery system, also started to appear. In fact this revolutionary change continued in the 90's making it complicated for hospitals to be able to define the exact duties of a material/resource manager (Simchi-Levi et al., 2003).

Within such a backdrop many countries were forced to start a national discussion to deal with the issue. This appeared to be even more important for Greece, where the problem was almost out of control. The common thread to all discussions was that the hospitals' costs should be decreased even if the materials managers' duties were still not defined. This demand resulted in the idea of uniting the material/resource management process and the achievement of optimum economies of scale for all entities of the system. The traditional approach to inventory management in hospitals dictates the administration and control of products, services and equipment from the moment of their purchase until the moment of their release (Martin, 1999). The meaning of this is that the buying, the receipt, the delivery, the storage and the distribution functions should be centralized. The most important dimensions of a 
material management program are: an appropriate strategy securing that materials (products, services, equipment) are bought in the lowest possible cost, an interrelated strategy which guarantees that the inventory and the costs are monitored and controlled and of course the availability of all the required material.

The purpose of this paper is to examine the distribution process of supplies, the amount or the volume of the medicine distributed and the degree of partnerships between Greek hospitals and their vendors. In this paper we examine the case of Greek public hospitals as for the ones in private sector there is a need for different approach regarding logistics functions. In addition, we monitor the extent of responsibility given to the logistics departments (if they do exist) with respect to purchasing, inventory management, internal distribution to medical departments and management information systems.

The driving forces behind this research have to do with the documented indisputable need for improving the effectiveness of medical logistics in the health care system worldwide and especially in the Greek case where the problem has taken great dimensions contributing up to a point to the creation of the big economic crisis. Since past surveys revealed high percentage of the hospitals' budgets spent for materials, consumables, equipment and outsourcing, a challenge was identified.

Could it be easy to identify and confirm what Bowersox and Closs supported in the difficult and special case of Greek hospitals? Was the centralized material management the solution to increasing costs as Hansen and Mowen suggested?

All the past surveys, and of course Nickolson's, were speaking for the great importance which should be given to the central inventory management in order to control expenses efficiently and the simultaneous implementation of just in time methods even though the exact duties of a material/resource manager were still under consideration (Simchi-Levi, 2003).

Our survey came to distinguish exactly the above in an environment where national discussions had been in process to deal with the issue of reducing hospitals' costs. Buying, receipt, delivery, storage and distribution functions should be monitored in the case of Greek hospitals. A significant goal was also to highlight through our survey the most important dimensions of a material management program.

The structure of the paper is as follows. In the next section the costs and administration of hospitals' output where the forms and types of possible costs are presented and analyzed while at the same time special reference is made to hospitals' procurement making a short analysis of the new procurement law of 2007. This was a rather controversial law which had as its main objective to improve the situation and reduce the wastes but actually created additional problems. The third section presents our survey and describes the research methodology and strategy followed, while in the fourth section we present the results derived from the seventeen questions of the questionnaire. In the fifth section those results are thoroughly analyzed and significant conclusions are stated. Finally in the last section, the epilogue, the findings of our research are summarized and future trends in the administration and purchase of materials in hospitals are suggested.

\section{Procurement in the Greek National Health System (N.H.S)}

In order to rationalize the administration of public money for the implementation of health policies, a new law (L.3580/2007) was voted with regard the purchasing systems of the health units. The new purchasing system:

- Collects the needs of hospitals in order to provide a common supply program and cover real and actual needs.

- $\quad$ Provides contracts which may cover various products and health services.

- $\quad$ Provides means of direct payment to the suppliers giving the chance of reducing the prices and the quantity of services bought.

- $\quad$ Creates a record for suppliers which can be regularly updated.

The Procurements' Health Committee (P.H.C) which is responsible among other things, for the elaboration of the terms and the specifications of the tenders, the contracts procedures and the setting of the economic transactions of hospitals, plays a significant role. For the first time in the N.H.S function the new law provided an integrated procurement system according to the European and national standards, guaranteeing in theory economies of scale, high quality of products and services, transparency and fair competition. According to the law the P.H.C is the superior managerial authority preserving functional and fiscal consistency and is responsible for the consolidation of the fragmented purchase system and continuously monitors the supply program of the hospitals. The work of the committee includes the consolidation of 3000 tenders held every year by 289 bodies of the N.H.S for the supply of 
500.000 kinds of medical products and 11.000 drugs from 1.144 suppliers. According to the Minister of Health, the new law would provide solutions to problems of the purchase system in the N.H.S and would also help save more than 500.000.000 Euros, which is an extremely high amount of money considering Greece's' debit and deficit nowadays.

The managerial structure of the P.H.C consists of six departments and three materialization units which hold the responsibility for the control of the supply chain and the implementation of the common supply program. The departments consist of the technology and supply chain administration department, the programming and evaluation department, the monitoring and controlling department, the specifications department, the pricing and quality department, the economical administration department, the supplies and revenues administration department and the technical support department. The three materialization units are the Research and Technology Pharmaceutics Institute, the Public Corporation of Building Hospitalization Units and the Biological Material Research Center. The three units are in close cooperation under the supervision of the P.H.C responsible to set declarations, to hold tenders and to execute contracts for services and products supplies. More specific the Research and Technology Pharmaceutics Institute is responsible for the tenders concerning the sanitary and orthopedic material, the reagents, the blood taking materials and the cardio logical surgery items, the blood cleaning filters and fuels. It is also responsible for the contacts and their control. The Public Corporation of Building Hospitalization Units on the other side has responsibility over the biomedical supplies, the contracts and the development of an internal network for the control of the receipt, the installation and function in N.H.S units. The Biological Material Research Center has the responsibility of creating and keeping a suppliers' record and a record of medical, technical and pharmaceutical products. At the same time it plays the role of a scientific counselor for the P.H.C suggesting the required technical specifications for the supply of biomedical and equipment and various medical products.

The P.H.C started its operations in 2008 and directly sent a relevant document to hospitals informing them that it would be the exclusive authority for all the procurement processes, whether conventional or unconventional. As a result, hospitals should first get the approval of the P.H.C for a supply to be valid. That would also be the case for the new contracts or tenders held between June 2007 and June 2008. After that, hundreds of requests started to come to the P.H.C offices for approvals. However, the committee operating with 25 employees could not check more that 25 requests per day while the coming number was about 45 requests per day. The ex-president of the P.H.C stated that the approvals need 1,5-2 months to materialize and the hospitals should take into account the time needed. Due to the conflicts that followed and in order to face the situation, the P.H.C decided to send details to hospitals to inform them further. Hospitals were informed that they would not need approval for the supplies related with the protection of life and security of the patients. The P.H.C gave to hospitals the chance to purchase products and services of low budgets provided that they report to the P.H.C every single month and set a limit of 3000-5000 Euros per month for unconventional expenses. Orders which were not in the framework would be executed normally by the suppliers without the approval of P.H.C. This policy was very beneficial to the improvement of the system. The amount of money spent for those supplies was about 200.000.000 euros in a fully uncontrolled environment. Moreover the P.H.C moved to the compilation of standard forms of declarations according to national and community law and to the compilation of common technical specifications for cleaning services and security services. Thus, the hospitals prepared tenders for cleaning and security services taking into consideration the declaration templates of P.H.C. However, due to the fact that in this way many Greek suppliers were eliminated and only two or three big companies could participate, the P.H.C forced for transparency reasons to abort all those tenders and give the direction to the hospitals to set new specifications according to the last declaration issue. Based on the above information we come to the conclusion that the new regime did not function as expected creating more problems and expenses enlarging the "black hole" of hospitals' deficits.

\section{Our Survey}

The first step of our study was to specify the main research question. The next step was to identify the parameters that are associated with the research question. This methodology helped us to identify and set the required limitations in our research. We tried to set realistic targets and develop our creativity for the finding of the appropriate research questions.

The research strategy followed is a combination of survey and case study, structuring and distributing a questionnaire and organizing interviews (over the phone and face to face). The questionnaire in its original form has been used for a previous survey that examined the differences in logistics between USA and French hospitals (Aptel and Pourjalali, 2001). The original questionnaire was of course adapted to suit the purposes for our survey. The questions address all logistics activities of public hospitals and the questionnaire itself was for the supervisors/managers of 
purchase/supplies department and/or material of warehouse supervisors/managers responsible for the researched operations. The purpose of the questionnaire was for fact finding and interpretation purposes, for outlining descriptions and for qualitative and quantitative analysis. The main research strategy followed was postal correspondence due to the fact that the receivers were located in different places all over Greece. This method usually has the drawback of low response rates (about 10\%), so we also made personal contacts and interviews and performed a telephone survey.

The process of questionnaires proves to have both advantages and disadvantages. Considering the advantages, the method approaches a large number of people or organizations (in our case we sent questionnaires to all public hospitals of Greece), it is a cost-effective and the researcher can easily code and analyze the results. Considering the drawbacks, we would include in these the small response rate, the varying academic and personal profile of the correspondents, the authority level and the available time for completion. In addition, it offers a medium level of validity and reliability since it records the personal view of the correspondent on the specific question. Due to this, this method needs to be supplemented with telephone conversations.

It is worth mentioning that a number of difficulties occurred regarding the questionnaire as a means of data collection for this work. These were the following:

- $\quad$ Since the target research group was the public hospitals, every questionnaire should have been registered as an official document with a protocol number and handed in by the sender personally, in order to be treated formally.

- $\quad$ There was great skepticism on whether public organizations should answer questions regarding the supply chain management and according to their claims it was the first time someone asked for such data.

- The decision on the person or employee to fill the questionnaire was complex for the majority of the recipients.

- $\quad$ Recurrent calls in each recipient were needed for receiving a positive or negative answer.

- In all cases a conversation and further qualifications were necessary for the filling of the questionnaire.

- Unfortunately during this year, the case of public hospitals and their extreme expenses combined with corruptions phenomenon in a general economic crisis environment, with judges to check thoroughly the illegal and irregular medical actions, the willingness of the hospitals to answer a questionnaire trying to find the existing procedures and asking for budgets was at an extremely low level.

- Due to a Greek journalist investigation about corruption in medical care procurement and supplies who was using a hidden camera to monitor some interviews revealing corruption in the supply chain of hospitals, some interviewers were afraid of participating in and consequently they did not accept to participate or avoided it by saying that it was not within their responsibilities.

The research covered all Greek public hospitals (a total of 133 public hospitals). The public hospitals in Greece are managed and controlled by The National Health Service and they run $71 \%$ of the hospital beds in Greece. The hospital or the Periphery Sanitary management was responsible for gathering the required documents from the researcher and the decision making was under the authority of the Scientific Council. After the suggestion of the Scientific Council and under the responsibility of the management of the hospitals, the documents received by the researcher were sent to the Ministry of Health and Social Solidarity for the final approval.

One hundred hospitals (100) hospitals out of the one-hundred and thirty three (133) received the questionnaire as an official document. Seventeen hospitals out of the one hundred thirty three finally responded during a time period of five months (s. Table 1). At the same time personal interviews took place in (5) hospitals of Athens and five (5) in top suppliers.

\section{Results}

The response rate was approximately $13 \%$, which is a small percentage but taking into account the current situation and regime which exists in Greek hospitals we could say that the result was satisfactory. The reasons for the low response rate were amongst others the extravagant bureaucracy dominating the hospitals' internal procedures and the time limitation. The questions of the questionnaire and the received answers are presented thoroughly below.

The first question was if the hospital had an in-house material management department and if so how it was called. The results came out of the above question were really impressive depicting either the lack of understanding of the question $(23.5 \%$ replied that they didn't know) or even worst the lack of such a department for a remarkable 
percentage of hospitals. The $52.9 \%$ replied that they do have a material management department. Different answers were given to the question for the different structure of each hospital and the complexity of the procedures. Specifically $11.1 \%$ replied that the special control of orders/warehouse department is the warehouse department, another $11.1 \%$ answered that this department was the supplies/purchase department/office, $44.4 \%$ said that the department responsible was the material administration department, $22.2 \%$ showed the material administration department in cooperation with another department and finally $11.1 \%$ responded the generally term "Warehouse and purchase department". It is obvious that the procedures seem to be heterogeneous enough proving that a stable and central organized procedure is not actually followed.

The second question and answer provided a picture on the areas of control that the main departments participating in the supply chain of hospitals hold. The results were expected and controversial at the same time. The $41.2 \%$ of the hospitals replied that drug supplies are handled by the pharmacy department, the $22.5 \%$ by the material administration department, $11.5 \%$ by the supplies/purchases department, $11.5 \%$ by a special logistics department and another $11.5 \%$ was not able to answer. As far as the medical consumables, $11.8 \%$ showed the pharmacy as the responsible department, $23.5 \%$ the material administration department, $58.8 \%$ the purchase/supplies department and $5.9 \%$ a special logistics department. About the reagents supplies according to our survey $17.6 \%$ answered that the pharmacy department is responsible, $29.4 \%$ the material administration, $41.2 \%$ the purchase department, $5.9 \%$ mentioned a special logistics department, and 5.9\% answered that they did not know. For the consumables in general on the other hand, $23.5 \%$ of the participants in the survey answered the material administration department, $70.6 \%$ the purchase/supplies department/office and the $5.9 \%$ a special logistics department. For the medical equipment purchases the impressive at the same time percentage of $94.1 \%$ of the responses showing the purchase/supplies department/office as the responsible department, despite that a $5.9 \%$ of the answers given mentioned the special logistics department. Physical supplies at the same time according to the $64.7 \%$ of the asked hospitals are handled by the purchase dept/office and $5.9 \%$ of them mentioned the existence of a special logistics department responsible for this activity, while $29.4 \%$ of them did not know. The activity of receiving is done by the $82.4 \%$ of the sample, while $17.6 \%$ reply that there is a special logistics department for this purpose. Furthermore, $82.4 \%$ of the hospitals say that the material administration of the warehouse is done by the material administration department and another $17.6 \%$ refer to a separate logistics department and 5.9\% state that they do not know. In addition, the $82.4 \%$ use the material administration department for the internal distribution of materials to the clinics and the $17.6 \%$ use a special logistics department. The management of informational systems of the hospitals belongs to the material administration department as it comes from the $17.6 \%$, whereas the $11.8 \%$ claims that it is the supplies' department authority and the $36.3 \%$ refers to a separate special logistics department, while $29 \%$ of the hospitals declares awareness. The nutrition supplies procedures are accomplished according to $17.6 \%$ of the receivers of the questionnaires by the material administration department, $23.5 \%$ by the purchase/supplies office, $47.1 \%$ by another special department and $11.8 \%$ does not answer at all stating awareness. For the distribution-transportation services the $23.5 \%$ of the sample allocates the procedures to the material administration dept, $17.6 \%$ to the purchase/supplies dept, 29.4 to a special logistics dept. and $29.4 \%$ is not aware. The duty of administrating the clothing supplies belongs to the $41.2 \%$ of the hospitals' sample to the material administration department, $23.5 \%$ to the purchase/supplies office, $23.5 \%$ to a special logistics department and $11.8 \%$ do not answer. In addition, care services for the $29.4 \%$ of the hospitals are handled by the supplies/purchase office, $5.9 \%$ by a special logistics dept and the impressive number of $64.7 \%$ do not know. This percentage implies the limited development and organization regarding care services. Telemedicine services seem to be an unknown field for public hospitals as $76.5 \%$ of the respondents declares total ignorance on the issue, $17.6 \%$ speak for a special logistics department handling the procedures and $5.9 \%$ show the purchase supplies office as responsible for telemedicine activities. The significant service of equipment maintenance is handled according to the $11.8 \%$ by the material administration department, by the purchase/supplies office according to $35.3 \%$ answered, a separate logistics dept according to $35.3 \%$ whereas a $17.6 \%$ cannot actually define. Finally, the environmental administration services are offered in line to the $47.1 \%$ of the answers by the supplies/purchase department/office, by a special logistics dept according to the $29.4 \%$ of the responses and another $11.8 \%$ declared total ignorance.

The third question was one of the most important queries for our research as this would help us identify which part of the supply chain plays a significant role in the distribution process. The distribution method plays a crucial role in logistics function influencing the purchase procedures and the workflows of supply chain in general. Thus, we can record the type of control implemented during the receipts of items by the suppliers and also monitor the distribution channel and check its efficiency. Seventy percent of hospitals answered that $0 \%$ of the value of the supplies are distributed directly from the suppliers to the clinics, $11.8 \%$ of them that the $1-25 \%$ of supplies' value is operated in 
the same way, $5.9 \%$ that the $26-50 \%$ of the purchases' value is delivered directly to the clinics, $5.9 \%$ that the value of supplies directly distributed is $51-75 \%$ and finally $5.9 \%$ of them were not aware. Referring to the percentage of supplies (in value) that are firstly stored in the central warehouse and then distributed by their distribution centers directly to the destination depts./clinics and used according to their needs, we found that $5.9 \%$ of the hospitals answered that the percentage of the value of supplies following this distribution method was $0 \%, 11.8 \%$ of them showed a percentage $1-25 \%, 5.9 \%$ a percentage of $26-50 \%, 17.6 \%$ a $51-75 \%$ percentage, $5.9 \%$ a $76-99 \%$ percentage and $41.2 \%$ answered that $100 \%$ of their supplies in values terms were following the specific method, while $11.8 \%$ of the sample stated not to have knowledge. The last distribution method examined was the percentage of supplies stored firstly in the central warehouse and distributed by their distribution center to separate warehouses of the destination clinics and then used depending on the needs created. The results showed a 17.6 population declaring that $0 \%$ of the supplies' value are handled in such a manner, $5.9 \%$ of hospitals said that this percentage was $1-25 \%$, another $5.9 \%$ that the ratio was $26-50 \%, 11.8 \%$ of them presented a $76-99 \%, 41.2 \%$ a $100 \%$ ratio and finally $17.6 \%$ replied nothing. We observed different procedures and the absence of standardization in the processes. However the common finding was that the central warehouse plays the dominant role holding the major responsibility for the distribution of materials. The difference was found in the way of distribution and a major factor for that was the size of the hospitals participated in the survey.

In the next question four suggestions were proposed by the researchers for the improvement of the materials' purchase procedures by the hospitals. Five different answers were available and the receivers could only choose one of them. The possible answers were: a) total disagreement, b) disagreement, c) Neutral opinion, d) total agreement, e) lack of awareness. In the question of whether the hospitals should reduce their stock, $5.9 \%$ of hospitals seemed to totally disagree, 11.8 to just disagree, $52.9 \%$ did not agree or disagree keeping neutral position and $29.4 \%$ of them appeared to agree. The alarming result of $52.9 \%$ who believe that the stock of their hospital should not decrease reveals indirectly the low use of logistics methods and the lack of an efficient control of the supply chain function. The big amount of stock in hospitals as we derived by the interviews, are created due to the lack of efficient logistics functions and the lack of MIS as the evaluation of stock required cannot be done effectively. This fact creates a sense of insecurity to the employees/supervisors responsible for the orders, supplies and materials administration. They only feel safe if maintain a large number of stock being able to fulfill the clinics' requests concerning the important material needed for the proper function of the hospital. About the second suggestion for reducing the number of their suppliers, $23.5 \%$ of the population totally disagreed and the $35.3 \%$ just disagreed, obviously in the scope of maintaining the existing competition which lowers the prices, while $29.4 \%$ kept a neutral behavior to that issue. No one answered positively to the question showing that the idea of stable relationships with suppliers is rather limited. An opportunism seems to derive by this trend as the low prices could also being achieved by co operating with less suppliers in a more closed relationship cooperation, system which could secure quality and better delivery or payment terms as well. The third suggestion for improving the relationships with suppliers was found to be the most popular one since $58.8 \%$ of the hospitals agreed and $29.4 \%$ totally agreed while a percentage of $11.8 \%$ remained neutral. Also very popular among the population seemed to be the fourth suggestion saying that hospitals should create new cooperation with other hospitals $(41.2 \%$ of the receivers of the questionnaires agreed and $17.6 \%$ agreed totally while $11.8 \%$ were neutral and another $11.8 \%$ disagreed). To summarize, most of the participants of the survey agreed on that public hospitals should be able to improve their relationships terms with the suppliers and create new co operations with other hospitals in order to improve their logistics functions and optimize the purchase procedures in the scope of reducing the money spent. At the same time they clearly disagreed with the idea of reducing numbers of suppliers, being cautious on whether they should reduce their stock of materials.

In the next question, we asked the authorized managers to estimate the total value of the stock of their hospital concerning the drugs, the medical consumables, the consumables in general and finally the total value of stock. The concept of the above question was to see the size of the hospitals participated in our survey and also monitor their capability of finding such data which are of great importance for the statistics and the strategy planning of a hospital. The use of MIS is necessary for the easiest and most accurate way of recalling such type of information and our question's findings proved that the efficient use of MIS is missing by the majority of the hospitals participated in the survey. From the interviews we made, we also observed lack of knowledge on the MIS capabilities. For example many hospitals answered telephonically that they do have and use a MIS in their hospital, despite that they do not know how to use all the possibilities and functions (Vagelatos and Sarivougioukas, 2003). The small response rate in written questionnaires cannot provide us with a generalized view of public hospitals. However, we are able to make a hypothesis based on the results of our survey. Commenting on the received results of the question, $47.1 \%$ of the answered questionnaires couldn't provide any number concerning the percentage of pharmacy stock value, the same 
ratio for the medical disposables (consumables) and the total stock value (also $47.1 \%$ ) and $58.8 \%$ of them couldn't specify the general disposable stock per hospital. That means that either the data was difficult to be extracted or the procedure of finding it was complex. In both cases the result is the same. Reduced monitor capability of logistics functions within the hospital. To be able to classify the size of the hospitals and depict them in charts we used a scale and numbered the answers. The answers we got for this specific question were very few and specifically nine (9) hospitals filled the percentage of the pharmacy stock, the same number the percentage of medical disposables, seven (7) of them the percentage of general consumables and nine (9) the percentage of the total stock value.

The answer to the question how the total value of stock is allocated through the central warehouse, the distribution centre, the clinics or other places, enabled us to observe which department maintains the most of the stock of the hospitals and to focus our investigation to the department which should implement the required techniques for improving the supply chain procedures. The central warehouse and the clinics/medical departments found to be the places where the most of the value of stock is gathered. The result was as expected but it was also realized by the telephone conversations with hospitals' employees (mainly supervisors) that there was not a standardized common policy as many differences were observed. The task of reducing the stocks of hospitals is of major importance for better economic performance. Under that scope we asked the hospitals of our survey to give as an answer on the issue whether their stock-keeping has reduced during the last three years. Emphasizing on this question and in order to monitor not only the actions taken but the trends as well, we set a six-possible answers choice. We found that $23.5 \%$ of the hospitals of our survey has seen a significant reduction probably because of new control techniques, $29.4 \%$ of them have seen a reduction and a $47.1 \%$ answered that the stock has remained almost the same.

The answers received in the question on the comparison of the number of suppliers that exist in hospitals now, in contrast with three years ago, showed that the number of suppliers in comparison with three years ago has either remained the same (58.8\% replied that), has increased or significantly increased. That means more competition but less stable and long-term co operations.

Another issue examined was the existence of a strategic alliance between hospitals on certain important issues such medical departments/clinic, medical staff, telemedicine, supplies/purchases, clothing laundry, nutrition/food service, environmental administration services, warehouse. The participants could fill more than one field. A percentage of $35.3 \%$ answered that such strategic alliances exist in medical departments/clinics, $17,6 \%$ said that they also exist in the medical staff, $41.2 \%$ replied that alliances between hospitals are implemented in the supplies procedures, $11.8 \%$ said the same for the nutrition services, the environmental administration services and the warehouse procedures, while $23.5 \%$ of the hospitals replied that they do not know or that such alliances does not exist at all (11.8\%). In addition, the possibility of strategic alliances between hospitals on certain programs was examined. More specific the question was if such strategic alliances exist, do they concern the following issues: a) JIT programs b) Lack of materials programs c) Electronic Data Interchange d) Supplier Certification. The $11.8 \%$ of the hospitals replied that JIT programs do exist under the scope of cooperation with other hospitals and $23.5 \%$ of them referred to the implementation of inventory reduction programs. A percentage of $11.8 \%$ referred to EDI concept and another $23.5 \%$ about the supplier certification issue. A percentage of $47.1 \%$ declared lack of information while $5.9 \%$ mentioned another field of cooperation existing between hospitals (common purchases).

Furthermore, the possibility for hospitals to have earned money due to efficient cooperation with suppliers was measured. The result was clear and the relevant figure showed that $70 \%$ of the hospitals participated in our survey did not manage to earn money and reduce their expenses due to a closer and better cooperation with the suppliers. A percentage of $6 \%$ answered that they did so and $24 \%$ were not able to define due to lack of evidence. Concerning the question on the specific amount of money earned, but unfortunately only one hospital answered the above questions in percentage terms. The answer was $7 \%$ of the overall budget.

Regarding the crucial issue of how likely is for hospitals to implement partnerships projects in certain issues in the next three years, we came up to significant conclusions for the hospitals' intention to implement modern partnership techniques in order to improve and optimize their supply chain reducing at the same time levels of corruption and bad administration phenomena appeared in the health care sector. That phenomena turned public national health system into a very costly system and that was a factor responsible for the existing economic crisis in our country. The results derived could be characterized as controversial enough as we find balance in answers. For example, half of the participants considered possible the hospital to implement a certain strategy for the following 3 years, and the other half of the participants declared that they considered that possibility as impossible. A well-organized supply chain requires all the above strategies to be implemented under the scope of strategic alliances between hospitals. A fully informed network will be thus created, making the information available to all relevant parties. 
The next question was to investigate the outsourced activities in hospitals and which part of certain activities is actually outsourced. Outsourcing is the process of contracting an outside company to provide a service previously performed in house. In many cases outsourcing involves a transfer of management responsibility for delivery of service and internal staffing patterns to an outside organization. Subcontracting, contracting out, staff augmentation, flexible staffing, employee leasing, professional services, contract programming, consulting and contract services are all terms which refer to outsourcing (Sarpin and Weideman, 1999). The conclusion derived from the relevant graphs and the interviews in hospitals is that outsourcing is growing and is growing in response to trends in the hospitals that are changing the way administrators view their organizations. Many managers in the purchase departments of hospitals believe that health care facilities could be outsourced as a possible response to demands created by market pressure, requirements of managed care organizations and increasing costs. Moreover as most supervisors of hospitals say, outsourcing seems to facilitate flexibility at a time when change seems to be the only constant. All the participants of the survey agreed on the fact that outsourcing in public health care organizations has a reasonable potential for further development and it is one of the best ways to reduce hospitals' costs ensuring quality assurance at the same time. A more flexible supply chain function is thus, enhanced.

Amongst others, the interviewed hospitals were asked to report the exact budget for the supplies of last year was asked to be reported by in order to consider capacity as a tool for our analysis. We also examined the response rate as a criterion for hospitals' awareness of the exact amount spent on purchases per year. The response rate was satisfying enough as $47 \%$ of hospitals included in the survey responded by providing the exact amount spent for supplies in 2009. The range for last year total budgets of hospitals suggests that small, medium and big hospitals participated in our research.

Finally, our survey showed that $5.9 \%$ of the employees completed the questionnaires were warehouse managers, $82.4 \%$ were purchase/supplies-dept/office managers and $11.8 \%$ held a different position, i.e. supervisor of economics sub department or were employed in the supplies department).

\section{Conclusions - Discussion}

Having completed and presented the results of our survey, our analysis should focus on the issues which had been set at the beginning of our survey. These issues were (i) the level of responsibility given to the logistics department for purchasing, receiving etc, (ii) the process of distribution of supplies (iii) the volume of supplies distributed (iv) the efforts made for the improvement of logistic processes (v) the level of partnerships between hospitals and their vendors and other hospitals.

According to our survey, considering facts of the Greek reality it seems that all functions of logistics go through the department of material administration or the purchase/supplies office. The central warehouse department plays a crucial role and it occurs that from time to time the supply chain management is handled by the cooperation of material administration department and the supplies office. We do not seem to get the picture of a logistics department as such through the questionnaire and that has to be noted. In the second question we included the term 'special department' amongst the departments that one could provide as an answer for controlling the orders of the warehouse and distribution. By this term we introduced a new type of department (logistics department) which proved to be as expected unknown to the Greek hospitals surveyed.

Regarding the process of distribution of materials to the clinics, it turned out a that there is only a small percentage of hospitals in which the supplier delivers directly to the clinic (in fact the real percentage hiding behind the formal answers is far more higher according to the suppliers and that is something that needs improvement). In all three cases the common action is that the materials are firstly stored in the central warehouse and thus the danger of loosing the control is less. Of course as we have mentioned previously other departments and procedures also get involved ensuring the required transparency and efficiency. The only problem is the lack of existence of a department having supervision of all procedures; from order to delivery.

Regarding the volume of supplies distributed, the process has been thoroughly analyzed before. The processes are different from hospital to hospital and the new law concerning procurement in public hospitals has played a crucial role. On the other hand we should pinpoint that the highest level of stock in terms of value is found in the central warehouse as (expected) of hospitals but also a significant percentage is allocated to the medical departments/clinics. This complies with our former reference concerning not only the hospital's policy but the new procurement law for hospitals as well.

Another finding of our survey depicted in the questionnaires was the willingness of the hospitals to improve their logistics' functions. They seemed positive in improving their cooperation with suppliers ensuring better delivery 
times, prices and quality of services and creating strategic alliances with other hospitals. Specifically as far as medical departments' partnerships approximately $42 \%$ answered that they consider it as possible while $30 \%$ considered it not. Regarding medical personnel alliances between hospitals, the percentage of those who predict future co operations found to be equal to the percentage of those who find such a case difficult. Regarding clothing laundry partnerships, they do not seem to have any potential as we see from the answers because these services are outsourced. The same situation is for the nutrition services whereas $48 \%$ thinks as rather impossible the occasion of partnerships. A $24 \%$ believes that it is likely to happen. For warehouse alliances and JIT systems no perspectives seem to exist. On the contrary stockless programs partnerships are considered by the $42 \%$ of the participants likely to emerge, however, a $30 \%$ of them find this perspective impossible. EDI also is considered a model for cooperation between hospitals by the $24 \%$ of the hospitals (Lim and Palvia, 2001).

Despite the efforts made and recorded by hospitals to improve the logistics function and optimize their supply chain, it seems that more efforts should be made as $47.1 \%$ of the hospitals in the survey declared that the inventory level of their hospital has remained the same during the last three years. The $52.5 \%$ of those answered that their inventory has been reduced as an effort of improving the supply chain procedures is considered rather significant.

Another result was that the number of suppliers during the last three years seems almost stable to $(58.8 \%$ of the answers) or increased (35.3\% of the answers). The increased number of suppliers probably explains the fact that compared to three years ago hospitals in a percentage of $70 \%$ did not earn any money because of good relationships with suppliers. This is absolutely logical from one point of view because the increase of suppliers is a reason for weak relationships. Competition may be enhanced but any special agreements could not be implemented in the scope of mass supplies or contracts.

To sum up, the results of our survey show fragmented logistics functions with a tendency to a more centralized logistics management system. The survey results also confirm the idea that logistics is considered as a significant factor for the development of interorganizational collaboration. Despite the fact that the logistics departments or those departments playing that role, are strengthened by improving or implementing partnerships and types of programs like JIT, the adaptation ratio of the above methods remains at low levels. Furthermore, although hospitals intend to continue their efforts in cost reduction by improving the current and future partnerships there is a significant number that do not identify the urgent need for further inventory reduction.

\section{Epilogue}

The main issue of our survey was the investigation of supply chain procedures in Greek public hospitals. The survey's scope was to provide some insights regarding the trends on this important topic. As it was observed the deficiencies of public hospitals regarding efficient techniques are substantial. The lack of organizational and strategic management procedures and the extremely inefficient administration of the resources dominate the results of our survey. Among other things we found that the internal cooperation between the departments of the hospitals create significant delays regarding the submission of the projects.

In addition, the lack of proper cooperation between departments creates either an automatic increase in hospitals' expenses or a lack of required materials. In both cases the final consumer is the one affected. As the cost control in healthcare has been the subject of many studies and different methods have been suggested in literature for reducing the cost of healthcare, our survey came to reconfirm the findings of the other researches and also suggests additional solutions. Our proposal is that the cost of carrying inventory can be reduced when activities are closely evaluated and non-value added activities are eliminated or minimized.

The future trends in the administration and purchase of materials are focused on the economies of scale, the lack of materials in hospitals, the environmental cost of hospitals, the lack of well trained employees and specialists, the cost of the materials and the limitations for imports and exports. Also the unification of quantities of materials with a reduced number of suppliers, longer time agreements with suppliers ensures reductions in the cost of administration, software capabilities development, EDI, improved inventory management, improvement of communication with suppliers, optimization of suppliers' performance, reduced delivery times and a great emphasis on quality.

\section{References}

Aptel, O., \& Pourjalali, H. (2001). Improving activities and decreasing costs of logistics in hospitals: a comparison of U.S. and French hospitals. The International Journal of Accounting, 36(1), 65-90.

Bowersox, D.J., \& Closs, D.J. (1996). Logistics Management: The integrated supply chain Process. New York, NY: Mc Graw -Hill. 
Hansen, D., \& Mowen, M. (1997). Cost management: accounting and control (2nd ed.). Cincinnati, OH: Sothwestern Collegge Publishing.

Lim D., \& Palvia P. (2001). EDI in strategic supply chain: impact on customer service. International Journal of Information Management, 21(3), 193-211.

Martin, C. (1999). Logistics and Supply Chain Management: Strategies for reducing cost and improving service (2nd ed.). International Journal of Logistics research and Applications, 2(1), 103-104.

Nicholson L., Vakharia A., \& Erenguc S. (2004). Outsourcing inventory management decisions in healthcare: Models and application. European Journal of Operational Research, 154(1), 271-290.

Sarpin, J., \& Weideman, G. (1999). Outsourcing in Health Care: The Administrator's Guide. AHA Press, Chicago.

Simchi-Levi D., Kaminsky P., \& Simchi-Levi E. (2003). Designing and managing the supply chain: concepts, strategies, and case studies. McGraw-Hill.

Vagelatos, A., \& Sarivougioukas. J. (2003). Regional Health Care Authorities delivering application services to primary health care units. Medical Informatics in Europe Conference, St Malo, France.

Wolper, L. F. (1995). Health Care Administration: Planning, Implementing and Managing Organized Delivery Systems $\left(3^{\text {rd }}\right.$ ed.). Jones \& Bartlett Publishers.

Table 1. The seventeen hospitals that responded to our survey

\begin{tabular}{|ll|}
\hline Hospital & Hospital \\
\hline - Onaseio Cardiological Center & - General Hospital of Giannitsa \\
- General Hospital of Naousa & - General Hospital of Corfu \\
- General Hospital of Rhodos & - General Hospital of Krestena \\
- General Hospital of Kefalonia & - General Hospital of Piraeus "Tzaneio" \\
- General Hospital of Lamia & - General Hospital of Salonica "Papageorgiou" \\
- General Hospital of Chalkida & - Hospital "Spiliopoulio Saint Helen”" \\
- Psychiatric Hospital of Athens "Dromokaiteio", & - General Hospital of Goumenissa \\
- General Hospital of Arta & - General Hospital of Larisa \\
- General Hospital of Elefsina "Thriasseio" & \\
\hline
\end{tabular}

